\title{
Exercise Training Attenuates Sympathetic Activation and Oxidative Stress in Diet-Induced Obesity
}

\author{
G. LI ${ }^{1}$, J.-Y. LIU ${ }^{1}$, H.-X. ZHANG ${ }^{1}$, Q. LI ${ }^{1}$, S.-W. ZHANG ${ }^{1}$ \\ ${ }^{1}$ Physical Education College, Northeast Normal University, Changchun, Jilin, China
}

Received June 12, 2014

Accepted November 13, 2014

On-line December 22, 2014

\section{Summary}

It is known that excessive sympathetic activity and oxidative stress are enhanced in obesity. This study aimed to clarify whether exercise training (ET) attenuates sympathetic activation and oxidative stress in obesity. The obesity was induced by highfat diet (HFD) for 12 weeks. Male Sprague-Dawley rats were assigned to four groups: regular diet (RD) plus sedentary (RD-S), RD plus ET (RD-ET), HFD plus sedentary (HFD-S), and HFD plus ET (HFD-ET). The rats in RD-ET and HFD-ET groups were trained on a motorized treadmill for $60 \mathrm{~min} /$ day, five days/week for 8 weeks. The sympathetic activity was evaluated by the plasma norepinephrine (NE) level. The superoxide anion, malondialdehyde and F2-isoprostanes levels in serum and muscles were measured to evaluate oxidative stress. The ET prevented the increases in the body weight, arterial pressure and white adipose tissue mass in HFD rats. The NE level in plasma and oxidative stress related parameters got lower in HFD-ET group compared with HFD-S group. We have found decreased mRNA and protein levels of toll-like receptor (TLR)-2 and TLR-4 by ET in HFD rats. These findings suggest that ET may be effective for attenuating sympathetic activation and oxidative stress in diet-induced obesity.

\section{Key words}

Exercise training - Sympathetic activation - Oxidative stress • Obesity • Toll-like receptor

\section{Corresponding author}

S.-W. Zhang, Physical Education College, Northeast Normal University, Renmin Street NO.5268, Changchun City, Jilin Province, China. E-mail: shouweizhang0705@163.com

\section{Introduction}

Obesity is recognized as a major global health concern which causes or exacerbates many health problems in children, adolescents and adults. Human obesity is characterized by the enhanced sympathetic activity, with the activation of the sympathetic nervous outflows to the heart, kidneys and skeletal muscle (Lambert G.W. et al. 2010). Sympathetic activity is closely associated with obesity-induced subclinical organ damage and function alterations in the young individuals (Lambert E. et al. 2010). The autonomic ganglion blockade caused a greater drop in arterial pressure in obese rats versus their lean counterparts (Schreihofer et al. 2005). The alpha- and beta-adrenergic blockaders caused greater decreases in blood pressure in obese patients compared with lean patients (Wofford et al. 2001). Excessive sympathetic activity plays a crucial role in the pathogenesis and target organ damage of the obesity (Dorresteijn et al. 2012).

It is known that oxidative stress is significantly enhanced in obesity (Dobrian et al. 2004). There were increased vascular endothelial expression of NADPH oxidase and elevated endothelial oxidative stress in overweight and obese adults compared with their normalweight peers (Silver et al. 2007). Jiang et al. (2011) also observed an up-regulated expression pattern of NADPH oxidase in vascular, adipose and kidney tissues in dietinduced obese rats. There were increased levels of reactive oxygen species in aortic endothelium and smooth muscle cells in Zucker obese fatty rats compared with Zucker lean rats (Pung et al. 2012). As a biological antioxidant, the alpha-lipoic acid showed a beneficial 
effect in the treatment of whole-body and skeletal muscle insulin resistance in obese rats (Muellenbach et al. 2008). The intracerebroventricular diphenyleneiodonium, a reduced NADPH oxidase inhibitor, elicited markedly greater reductions in renal sympathetic activity and arterial pressure in the obesity rats than control rats (Nagae et al. 2009). Oxidative stress is involved in the development of obesity (Furukawa et al. 2004).

Excess weight is established as a major risk factor for cardiovascular diseases. Physical activity contributes to the control of blood pressure in both overweight and lean subjects (Fagard 1999). Physical activity was effective in reducing sympathetic and parasympathetic nervous activities in obese children (Nagai and Moritani 2004). The exercise training (ET) is beneficial for cardiovascular health of patients with type 2 diabetes mellitus and hypertension (Stewart 2002). A randomized controlled trial showed that ET can reduce resting sympathetic activity in heart failure patients (Roveda et al. 2003). ET can also normalize enhanced sympathetic activation in rats with heart failure (Kleiber et al. 2008). The moderate exercise significantly decreased the aging-associated development of oxidative stress (Navarro et al. 2004). We hypothesize that ET can attenuate sympathetic activation and oxidative stress in diet-induced obesity. Moreover, toll-like receptors (TLRs) have been confirmed to participate in the molecular links between inflammation, metabolism and obesity (Fresno et al. 2011). TLR stimulation contributes to the pathogenesis of obesity (Francaux 2009, Fresno et al. 2011). As members of TLR family, TLR-2 and TLR-4 are widely present in liver, adipose tissue and muscle (Francaux 2009, Frisard et al. 2010, Milanski et al. 2009). Therefore, we determined the alteration of TLR-2 and TLR-4 in muscles of high-fat diet (HFD)-fed rats after ET. This study aimed to clarify the therapeutic effect of ET on sympathetic activation and oxidative stress in diet-induced obesity.

\section{Materials and Methods}

\section{Animal and induction of obesity}

One hundred and twenty-eight male SpragueDawley (SD) normotensive rats weighing between 300 and $350 \mathrm{~g}$ were used to induce obesity with a HFD for 12 weeks. The rats were randomly assigned to receive a regular diet [RD; $12 \% \mathrm{kcal}$ as fat, $20 \% \mathrm{kcal}$ as protein, $68 \% \mathrm{kcal}$ as carbohydrate] or HFD [42\% kcal as fat (39\% saturated, $45 \%$ monounsaturated and $11 \%$ polyunsaturated), $20 \% \mathrm{kcal}$ as protein, $38 \% \mathrm{kcal}$ as carbohydrate] for 12 weeks. The formula of standard rat chow in RD contained the standard powder $35 \mathrm{~g}$, wheat bran $15.5 \mathrm{~g}$, corn flour $20 \mathrm{~g}$, soybean meal $20 \mathrm{~g}$, soybean oil $0.5 \mathrm{~g}$, fish meal $5 \mathrm{~g}$, bone meal $2.5 \mathrm{~g}$, yeast extract $1 \mathrm{~g}$, and salt $0.5 \mathrm{~g}$ in each $100 \mathrm{~g}$. The formula of HFD was given as follows: each $100 \mathrm{~g}$ contains standard rat diet $60 \mathrm{~g}$, lard $13 \mathrm{~g}$, casein $5 \mathrm{~g}$, skim milk $8 \mathrm{~g}$, dried egg yolk powder $10 \mathrm{~g}$, sugar $4 \mathrm{~g}$. The RD group was again randomly subdivided into two subgroups: $\mathrm{RD}$ plus sedentary (RD-S) and RD plus ET (RD-ET). Similarly, the HFD group was subdivided into HFD plus sedentary (HFD-S), and HFD plus ET (HFD-ET) subgroups.

All rats were housed in a temperature- and humidity-controlled room with a constant light-dark cycle (12 h/12 h) and were maintained on ad libitum food and water. The experimental procedures were approved by the Experimental Animal Care and Use Committee of Northeast Normal University and complied with the Guide for the Care and Use of Laboratory Animals (NIH Publication No. 85-23, revised 1996). Acute experiments were performed under anesthesia induced by intraperitoneal injection of urethane $(800 \mathrm{mg} / \mathrm{kg})$ and a-chloralose $(40 \mathrm{mg} / \mathrm{kg})$. When an adequate depth of anesthesia was attained, supplementary doses of urethane and a-chloralose were given approximately during experiments. Six of the initial 128 rats were excluded because of death and technical problems. There were one in RD-S, three in RD-ET, and two in HFD-S. The rats in Figures 4 and 5 were the same rats.

\section{Treadmill exercise}

A standardized ET was performed at the end of the 4th week of diet and continued for 8 weeks until the 12th week of diet. According to the previous reports (Melo et al. 2009, Yamaguchi et al. 2013), rats in RD-ET and HFD-ET groups were trained on a motorized treadmill at $18 \mathrm{~m} / \mathrm{min}$ for $60 \mathrm{~min} /$ day, five days/week for 8 weeks. The animals of other two groups were handled daily and subjected to the noise of the running treadmill by placing their cages next to the treadmill when their ET-matched partner ran on the treadmill. This procedure was designed to minimize any possible confounding effect of external factors (e.g. handling, treadmill noise) on the dependent variables.

\section{Measurement of body weight and systolic blood pressure}

Body weight (BW) and systolic blood pressure (SBP) of tail artery were measured in a conscious state 
at weekly intervals. The SBP was measured with a noninvasive computerized tail-cuff system (NIBP, ADInstruments, Sydney, Australia). In order to detection of tail artery pulsations at a steady level, the rats were warmed for about $10-20 \mathrm{~min}$ at $28^{\circ} \mathrm{C}$ before the measurements. A set of 10 measurements was collected and then averaged to obtain the SBP for every animal. At the end of the experiment, epididymal, inguinal, mesenteric and retroperitoneal fad pads as well as heart were harvested and weighed. A blood sample was taken $30 \mathrm{~min}$ after the exposure of the trachea and carotid artery for measurement of plasma norepinephrine (NE), serum malondialdehyde (MDA), superoxide anion and F2-isoprostanes (F2-IsoPs).

\section{Measurement of $N E$}

The 5-ml sample of blood was collected from the right carotid artery into Vacutainer tubes containing potassium-ethylene diamine tetraacetic acid. It was centrifuged at 13,000 $\mathrm{g}$ for $5 \mathrm{~min}$ and then the supernatant was collected. Plasma NE level was measured with commercial ELISA kits according to the manufacturer's instructions. Samples and diluent buffer were added, incubated and washed. Horseradish peroxidaseconjugated $\mathrm{IgG}$ preparations were added and then washed out. The reactions were stopped by the addition of stop solution, and the absorbance was read at $450 \mathrm{~nm}$ by using the Bio-Tek ELx800 reader.

Pharmacological analysis of peripheral sympathetic tone The response of mean arterial pressure (MAP) to ganglionic blockade was used to evaluate basal sympathetic nerve activity as previously reported in conscious rats (Fan et al. 2012). A depressor effect was induced by intravenous administration of hexamethonium $(30 \mathrm{mg} / \mathrm{kg}$ ). The maximal decrease in the MAP was considered as an index of sympathetic activity.

\section{Monitoring mean artery pressure}

The MAP was recorded in anesthetized state induced by intraperitoneal injection of urethane $(800 \mathrm{mg} / \mathrm{kg})$ and a-chloralose $(40 \mathrm{mg} / \mathrm{kg})$. The rat was ventilated with room air using a rodent ventilator (683, Harvard Apparatus, Inc.). The right carotid artery was cannulated for continuous recording of MAP on a PowerLab data acquisition system (8SP, ADInstruments, Australia).

\section{Measurement of MDA levels in muscles and serum}

The 50-mg samples of soleus and ventricle muscles were removed quickly, flash-frozen in liquid nitrogen, homogenized, centrifuged and alloquated. The Bradford assay was employed to measure the protein concentration in the supernatant. Measurement of MDA was widely used as an indirect marker of oxygen free radical as previously reported (Hussein et al. 2014). The absorbance of diadduct formed by the thiobarbituric acid reaction with MDA was read at a wavelength of $532 \mathrm{~nm}$. The MDA levels were expressed as nanomoles per milligram of tissue protein ( $\mathrm{nmol} / \mathrm{mg}$ protein) in muscles or nanomoles per litre of serum (nmol/l), respectively.

Measurement of superoxide anion levels in muscles and serum

Lucigenin-derived chemiluminescence is most noted as a detector of superoxide anion. Lucigenin can react with superoxide anion to yield unstable dioxetane intermediate, which can break down into two molecules of N-methylacridone (Chou et al. 2004). Only the molecular in electronically excited singlet state can emit a photon, which can be measured with a luminometer (20/20n, Turner, CA). Background chemiluminescence in the buffer containing lucigenin $(5 \mu \mathrm{M})$ was measured. Values representing the superoxide anion levels were expressed as mean light unit (MLU) per minute per milligram of protein (MLU/min/mg protein) in muscles or MLU per litre of serum (MLU/min/l), respectively.

Measurement of F2-isoprostanes levels in muscles and serum

F2-isoprostanes (F2-IsoPs), specific products of free radical-induced lipid peroxidation, is widely used as index of oxidative stress in vivo (Vernunft et al. 2014). The levels of F2-IsoPs in muscles and serum were measured with commercial ELISA kits (Blue Gene, Shanghai, China) according to the manufacturer's instructions. Values representing the F2-IsoPs levels were expressed as nanograms per milligram of tissue protein (ng/mg protein) in muscles or nanograms per litre of serum (ng/l), respectively.

\section{Protein extraction and fractionation}

The 50-mg sample of soleus and ventricle muscles were chopped and homogenized under ice-cold conditions in $1 \mathrm{ml}$ of ice-cold lysis buffer $(1.5 \mathrm{mM}$ $\mathrm{MgCl}_{2}, 10 \mathrm{mM} \mathrm{NaCl}, 20 \%$ glycerol, $20 \mathrm{mM}$ HEPES $\mathrm{pH}$ 7.6, $0.1 \%$ Triton X-100, $1 \mathrm{mM}$ dithiothreitol). The 
muscle homogenates were centrifuged at $1000 \mathrm{rpm}$ for $1 \mathrm{~min}$ at $4{ }^{\circ} \mathrm{C}$. The supernatants containing the cytoplasmic protein fraction were collected and subjected to protein assay via Bradford assay.

\section{Western blotting}

Equivalent amounts of proteins were separated by $10 \%$ SDS-PAGE, transferred to a nitrocellulose membrane (Pall, Pensacola, FL, USA) and immunoblotted with primary antibody to toll-like receptor (TLR)-2 (1:300, Santa Cruz Biotechnology, Santa Cruz, CA, USA) or TLR-4 (1:300, Santa Cruz Biotechnology, Santa Cruz, CA, USA). The secondary antibody, biotinylated goat anti-rabbit $\mathrm{IgG}$, was used in a dilution of 1:5000. After incubated with enhanced chemiluminescence (Pierce, Rockford, IL, USA) and visualized by exposing to BioMax films (Kodak, Rochester, NY, USA), the membranes were stripped and sequentially immunoblotted with a mouse monoclonal anti- $\beta$-actin primary antibody (1:300, Santa Cruz Biotechnology, Santa Cruz, CA, USA) and rabbit antimouse secondary antibody. The results were expressed as the ratio of the optical density value of the interested band to $\beta$-actin band.

\section{Quantitative real-time PCR}

Total RNA was extracted from soleus and ventricle muscles with TRIzol reagent (Sigma-Aldrich, St. Louis, Missouri, USA) according to the manufacturer's protocols. The RNA samples were solubilized in RNase-free $\mathrm{H}_{2} \mathrm{O}$ and then quantified by measuring the value of optical density (OD) at $260 \mathrm{~nm}$. Purity of RNA was assured by examining the OD260/OD280 ratio of approximately 2.0. RNA was reverse transcribed to cDNA with the cDNA synthesis kit (Fermentas, Germany) according to the manufacturer's protocols. One microliter of cDNA was then amplified by PCR using $100 \mathrm{ng}$ of each primer, $250 \mu \mathrm{M}$ deoxyribonucleotide triphosphates (dNTPs), 1× PCR buffer, and 2 units Taq DNA polymerase (Sigma, St. Louis, MO, USA) and SYBR green dye diluted 1:2500 (Sigma, St. Louis, MO, USA) in a final volume of $20 \mu \mathrm{l}$. Primer pairs were designed against TLR2 (forward, 5'-GAAAGATGCGCTTCCTGAAC-3'; reverse, 5'-CGC CTAAGAGCAGGATCAAC-3'), TLR4 (forward, 5'-GC CGGAAAGTTATTGTGGTGGT-3'; reverse, 5'-ATG GGTTTTAGGCGCAGAGTTT-3') and $\beta$-actin (forward, 5'-GCCATGTACGTAGCCATCCA-3'; reverse, 5'-GAA CCGCTCATTGCCGATAG-3'). The $\beta$-actin was adopted as an endogenous reference compared to the expression levels of both TLR2 and TLR4. The PCR reaction was performed according to a modified protocol on the 7500 Fast Real-Time PCR System (Applied Biosystems) at $95^{\circ} \mathrm{C}$ for $10 \mathrm{~min}$, followed by 40 cycles of $95^{\circ} \mathrm{C}$ for $15 \mathrm{~s}$ and $60^{\circ} \mathrm{C}$ for $1 \mathrm{~min}$. The $2-\Delta \Delta \mathrm{Ct}$ method was used to calculate the relative expression levels of both TLR2 and TLR4 in each group.

\section{In situ detection of superoxide anions}

The in situ detection of superoxide anions in soleus and ventricle muscles was carried out with specific fluorogenic probe dihydroethidium (DHE) as previously reported (Zimmerman et al. 2004). The rats were euthanized with a single intravenous overdose of sodium pentobarbital. Within 1-2 min, the soleus and ventricle muscles were rapidly removed, frozen in liquid nitrogen, immediately embedded and cryostat sectioned (20 $\mu \mathrm{m}$; coronal) directly onto pre-chilled microscope slides. Then, the slides were thawed at room temperature and rehydrated with phosphate-buffered saline (PBS) followed by $5 \mathrm{~min}$ incubation with $1 \mu \mathrm{M}$ DHE in the dark. After washing with PBS twice, DHE fluorescence was visualized by a laser scanning confocal microscopy (LSM510, Carl Zeiss, Germany) with 543-nm excitation. Laser intensity and detector settings were kept constant during experiment. The fluorescence was quantified and the fluorescence integral optical density (IOD) was compared.

\section{Statistical analysis}

The SPSS 18.0 for Windows was adopted in the data analysis. All data were expressed as mean $\pm \mathrm{SE}$. Comparisons between 2 observations in the same rat were assessed by Student paired t test. ANOVA followed by post-hoc Bonferroni test was applied when multiple comparisons between different groups were made. A value of $\mathrm{P}<0.05$ was considered statistically significant.

\section{Results}

\section{Anatomic data, blood pressure and HR}

The BW (Fig. 1A) and SBP of tail artery (Fig. 1B) were higher in HFD-S rats than RD-S or RD-ET rats. The HFD-S rats had increased final BW, BW gain, heart weight (HW), white adipose tissue (WAT) mass, adiposity index and MAP compared with RD-S or RD- ET rats (Table 1). ET can prevent the 
increases in the above abnormal anatomic data and MAP in HFD rats, but still significantly different from RD-S or RD-ET (Table 1).

Basal sympathetic activity

Both plasma NE level and maximal hexamethonium-induced depressor responses were applied to evaluate basal sympathetic activity. Compared with RD-S or RD-ET rats, the HFD-S rats exhibited a higher plasma NE level (Fig. 1C) and a greater depressor response (Fig. 1D), which were attenuated by ET.

Table 1. Anatomic data, MAP and heart rate after 12 weeks of diet.

\begin{tabular}{|c|c|c|c|c|}
\hline Variables & RD-S & RD-ET & HFD-S & HFD-ET \\
\hline$n$ & 31 & 29 & 30 & 32 \\
\hline Initial $B W, g$ & $317 \pm 3$ & $321 \pm 4$ & $312 \pm 6$ & $315 \pm 6$ \\
\hline Final $B W, g$ & $463 \pm 6$ & $454 \pm 7$ & $655 \pm 11 * \dagger$ & $594 \pm 12 *+t$ \\
\hline$B W$ gain, $g$ & $165 \pm 7$ & $156 \pm 6$ & $330 \pm 12 * \dagger$ & $288 \pm 13 *+t$ \\
\hline Final $B W$ range, $g$ & $362-552$ & $340-551$ & $562-826$ & $546-760$ \\
\hline$H W, m g$ & $1528 \pm 14$ & $1493 \pm 15$ & $2168 \pm 29 * \dagger$ & $1962 \pm 27 *+t$ \\
\hline$H W / B W, m g / g$ & $3.28 \pm 0.04$ & $3.22 \pm 0.05$ & $3.35 \pm 0.05$ & $3.29 \pm 0.06$ \\
\hline Inguinal WAT mass, $g$ & $7.5 \pm 0.4$ & $6.2 \pm 0.4$ & $17.8 \pm 0.5^{* \dagger}$ & $14.2 \pm 0.4 *+t$ \\
\hline Retroperitoneal WAT mass, $g$ & $8.1 \pm 0.5$ & $7.3 \pm 0.3$ & $15.6 \pm 0.3^{* \dagger}$ & $11.3 \pm 0.4 *+t$ \\
\hline Epididymal WAT mass, $g$ & $4.2 \pm 0.2$ & $3.6 \pm 0.5$ & $9.7 \pm 0.3 * \dagger$ & $7.5 \pm 0.2 *+t$ \\
\hline Mesenteric WAT mass, $g$ & $4.4 \pm 0.1$ & $3.9 \pm 0.2$ & $8.5 \pm 0.4 * \dagger$ & $6.1 \pm 0.5 *+t$ \\
\hline Sum of WAT mass, $g$ & $24.8 \pm 0.5$ & $22.3 \pm 0.4$ & $51.2 \pm 1.2 * \dagger$ & $39.5 \pm 0.9 * \dagger+$ \\
\hline Adiposity index, $\%$ & $5.6 \pm 0.2$ & $5.1 \pm 0.2$ & $8.2 \pm 0.3 * \dagger$ & $7.6 \pm 0.2 * \dagger+$ \\
\hline$M A P, m m ~ H g$ & $93.2 \pm 1.9$ & $89.5 \pm 1.5$ & $126.7 \pm 2.8 *+t$ & $112.5 \pm 2.1 *+t$ \\
\hline Heart rate, bpm & $342 \pm 6$ & $350 \pm 8$ & $362 \pm 7$ & $354 \pm 11$ \\
\hline
\end{tabular}

Values are mean $\pm \mathrm{SE}$. MAP and heart rate were determined under anesthesia. ${ }^{*} \mathrm{P}<0.05$ vs. RD-S; $+\mathrm{P}<0.05$ vs. RD-ET; $\neq \mathrm{P}<0.05$ vs. HFD-S.

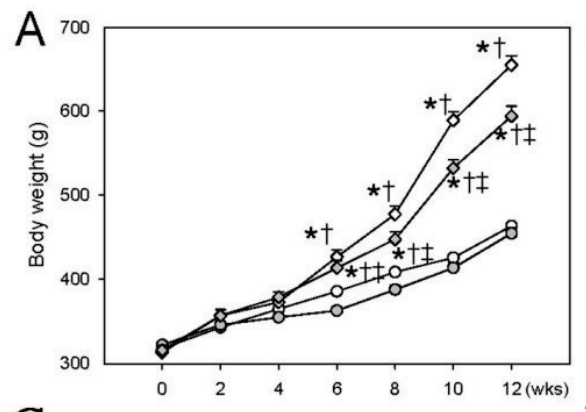

$\mathrm{C}$

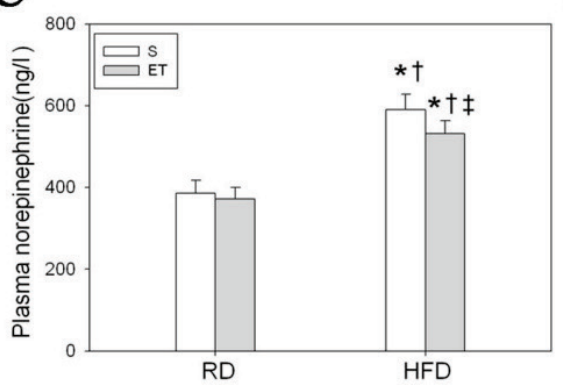

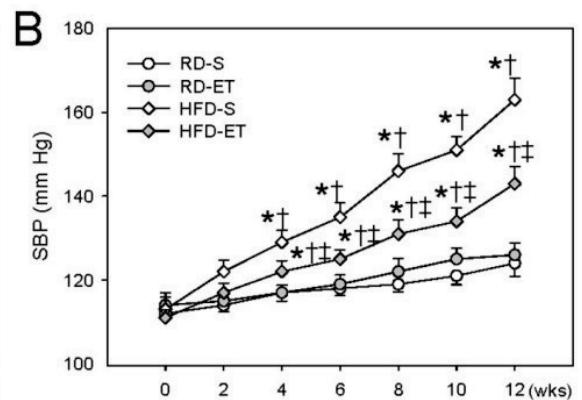

D

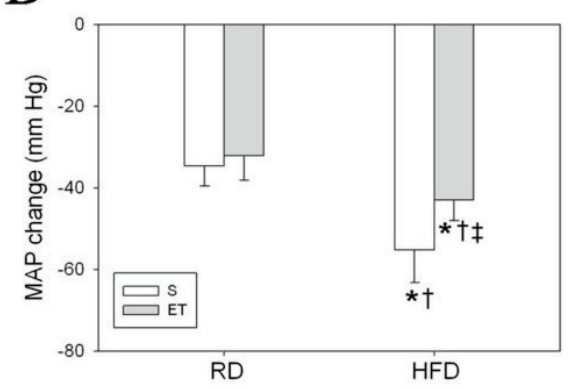

Fig. 1. BW (A), SBP of tail artery (B), plasma NE level (C) and maximal hexamethonium-induced depressor responses (D) of rats with different treatment. BW and SBP of tail artery were measured in conscious state during the 12 weeks of diet, while other parameters were measured at the end of the 12th week of diet. Values are mean $\pm S E ; n=8$ for each group. $* \mathrm{P}<0.05$ vs. RD-S; $+\mathrm{P}<0.05$ vs. RD-ET; $¥ \mathrm{P}<0.05$ vs. HFD-S. 

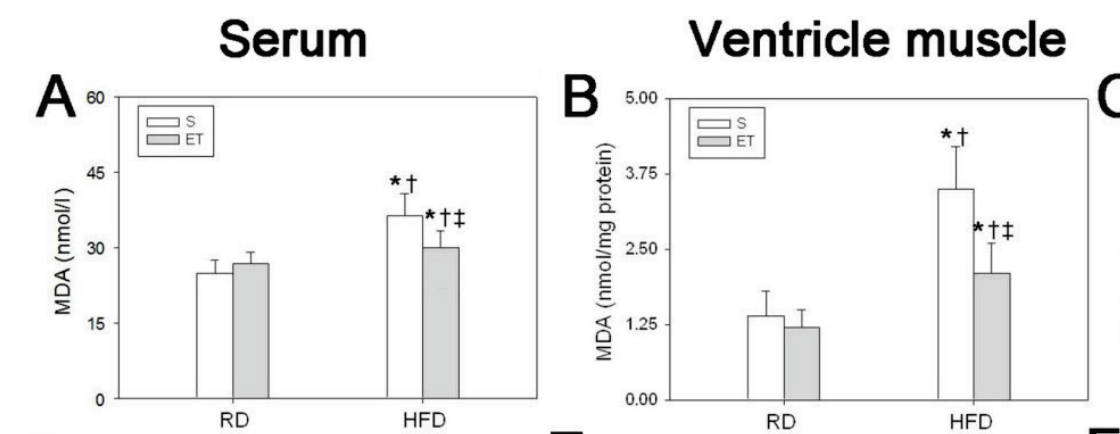

\section{Soleus muscle}
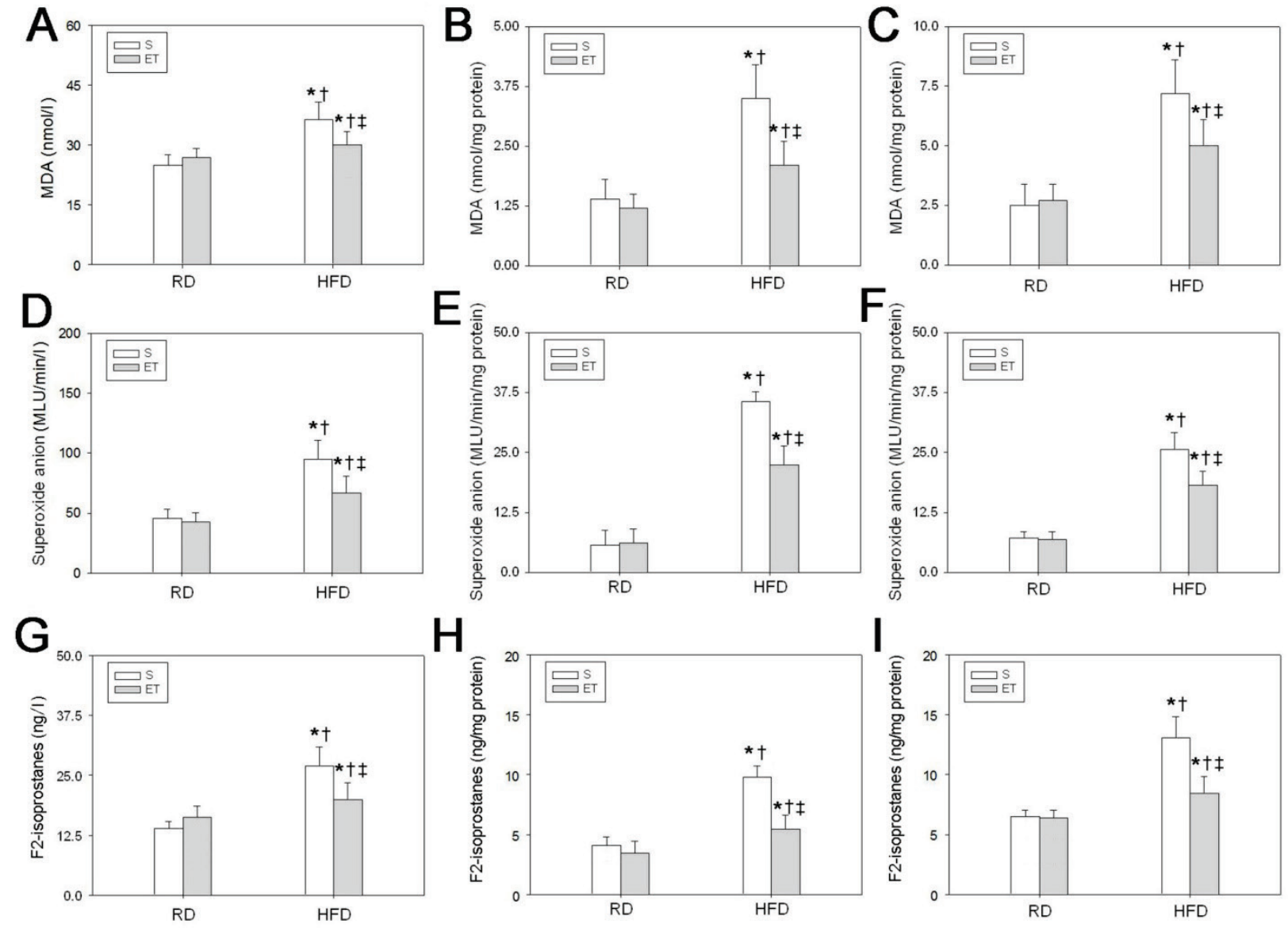

Fig. 2. The MDA, superoxide anion and F2-IsoPs levels in muscles and serum of rats with different treatment at the end of the 12th week of diet. A, B, C: MDA levels in serum, ventricle and soleus muscle; D, E, F: superoxide anion levels in serum, ventricle and soleus muscle; G, H, I: F2-IsoPs levels in serum, ventricle and soleus muscle. Values are means $\pm \mathrm{SE} ; \mathrm{n}=8$ for each group. ${ }^{*} \mathrm{P}<0.05$ vs. RD-S; $+P<0.05$ vs. RD-ET; $\neq P<0.05$ vs. HFD-S.

\section{The MDA levels in muscles and serum}

Compared with RD-S or RD-ET rats, the MDA levels in HFD-S rats were increased in both serum (Fig. 2A) and muscles (Figs 2B and 2C). The ET decreased the elevated levels of MDA in serum, soleus and ventricle muscles, which were still different from $\mathrm{RD}-\mathrm{S}$ or RD-ET rats.

\section{The superoxide anion levels in muscles and serum}

Compared with RD-S or RD-ET rats, the superoxide anion levels in HFD-S rats were increased in both serum (Fig. 2D) and muscles (Figs 2E and 2F). The ET decreased the elevated levels of superoxide anion in serum, soleus and ventricle muscles, which were still different from RD-S or RD-ET rats. The results showed that the changes of superoxide anions measured by in situ detection were consistent with the statistical results of method of lucigenin-derived chemiluminescence (Fig. 3).

\section{The F2-IsoPs levels in muscles and serum}

Compared with RD-S or RD-ET rats, the F2-IsoPs levels in HFD-S rats were increased in both serum (Fig. 2G) and muscles (Figs $2 \mathrm{H}$ and 2I). The ET decreased the elevated levels of F2-IsoPs in serum, soleus and ventricle muscles, which were still different from $\mathrm{RD}-\mathrm{S}$ or RD-ET rats.

The protein and mRNA levels of TLR-2 and TLR-4 in muscles

The protein and mRNA levels of TLR-2 and TLR-4 was increased in soleus (Fig. 4) and ventricle muscles (Fig. 5) of HFD-S rats versus RD-S or RD-ET rats. The ET decreased the elevated levels of TLR-2 and TLR-4 in soleus muscles, which were still different from RD-S or RD-ET rats. 


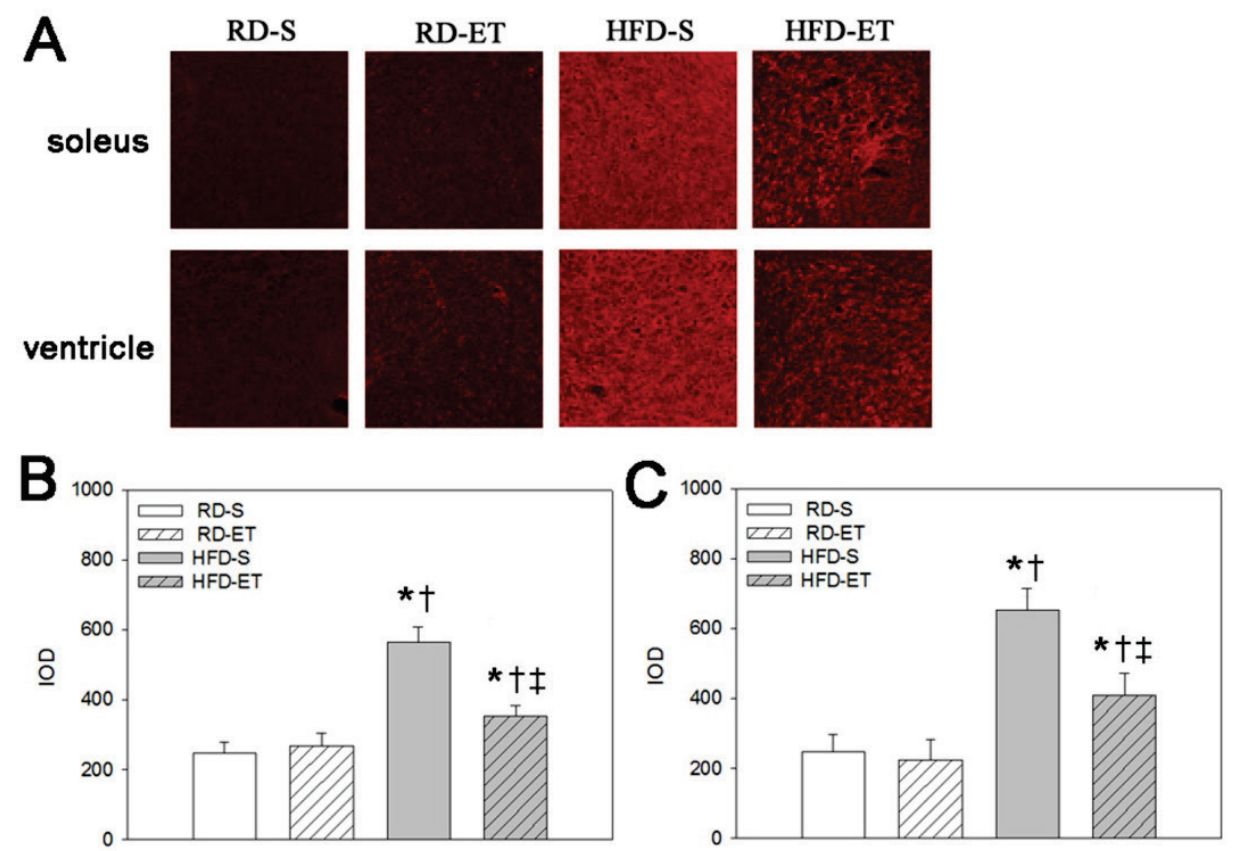

Fig. 3. The representative recording (A) of superoxide anion levels in muscles of rats with different treatment determined with DHE method at the end of the 12 th week of diet. B: IOD of soleus muscle; $\mathbf{C}$ : IOD of ventricle muscle. Values are mean $\pm S E ; n=6$ for each group. $* \mathrm{P}<0.05$ vs. RD-S; $+\mathrm{P}<0.05$ vs. RD-ET; $\neq \mathrm{P}<0.05$ vs. HFD-S.
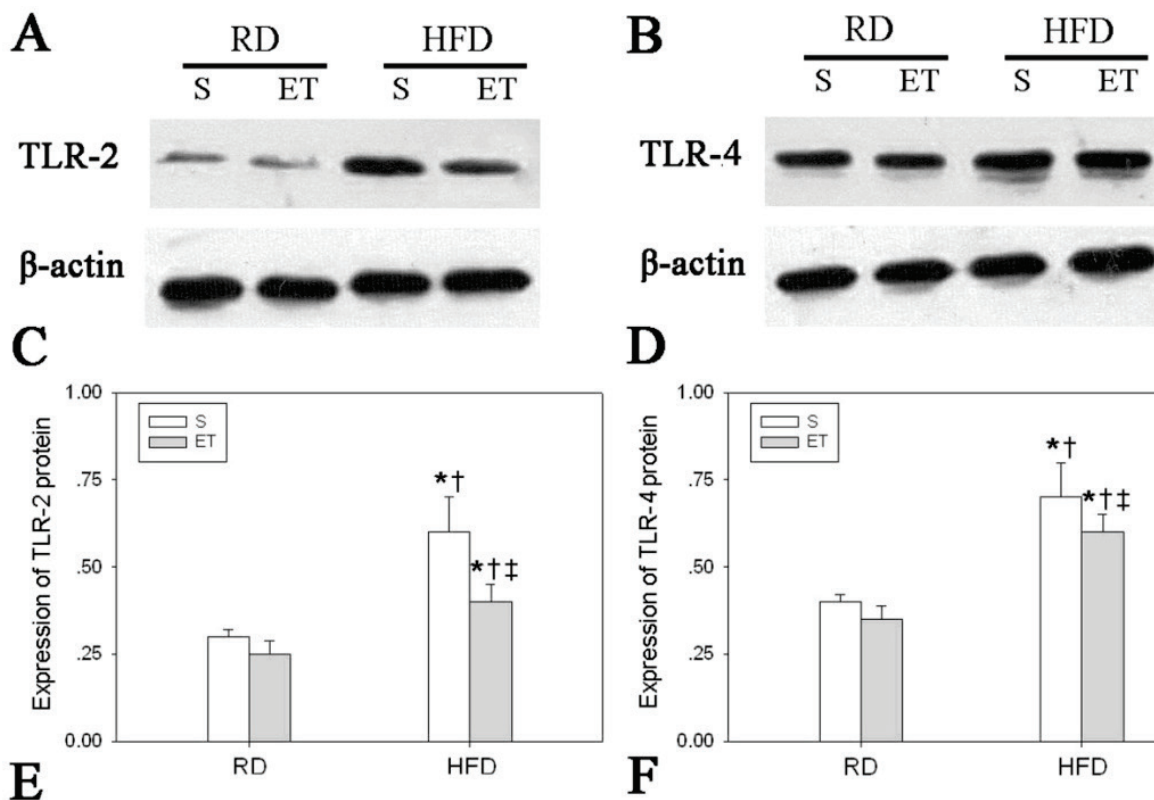

TLR-4

\section{$\beta$-actin}

D
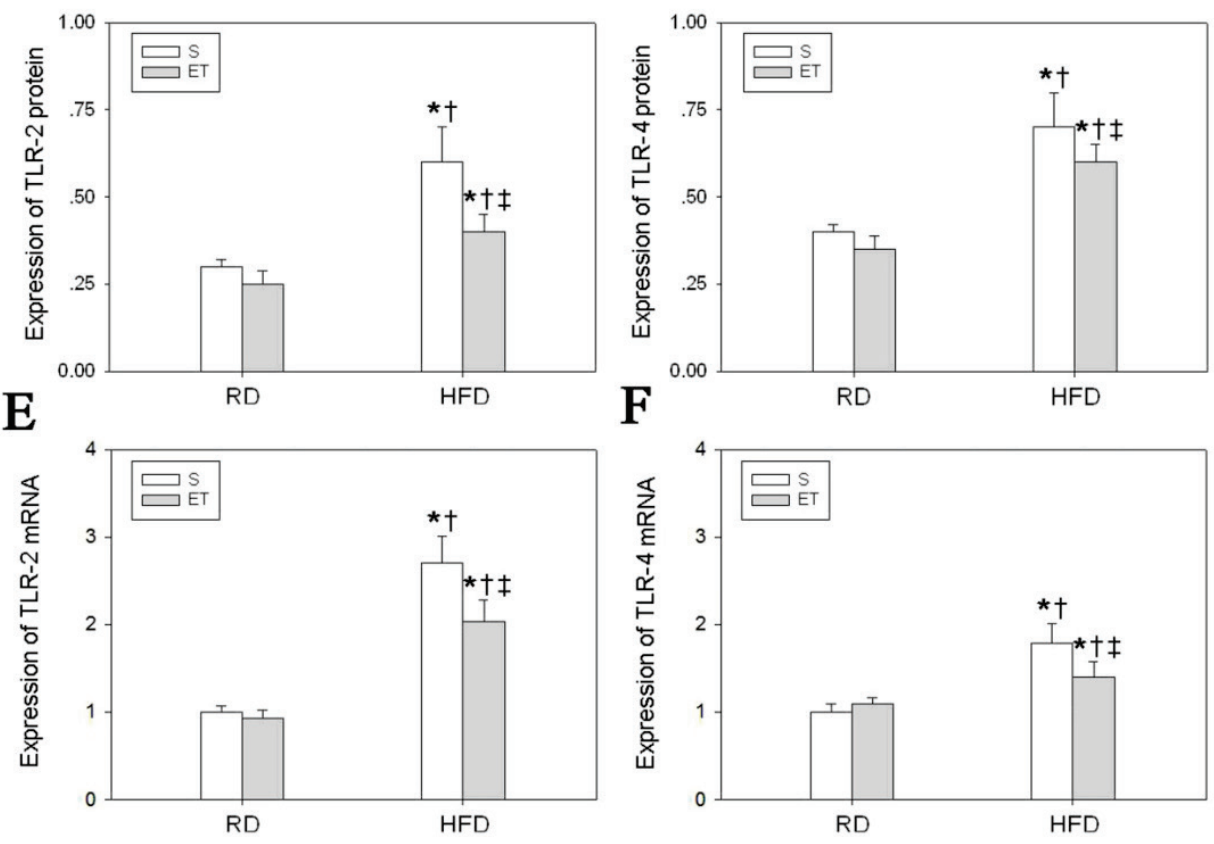

Fig. 4. The TLR-2 and TLR-4 expression in the soleus muscles of rats with different treatment at the end of the 12th week of diet. The protein was determined with Western blot and was expressed as the ratio to $\beta$-actin. A, B: Original recording for TLR-2, TLR-4; C, D: Protein levels of TLR-2, TLR-4; E, F: mRNA levels of TLR-2, TLR-4. Values are mean \pm SE; $n=6$ for each group. $* P<0.05$ vs. RD-S; $+\mathrm{P}<0.05$ vs. RD-ET; $\neq \mathrm{P}<0.05$ vs. HFD-S. 

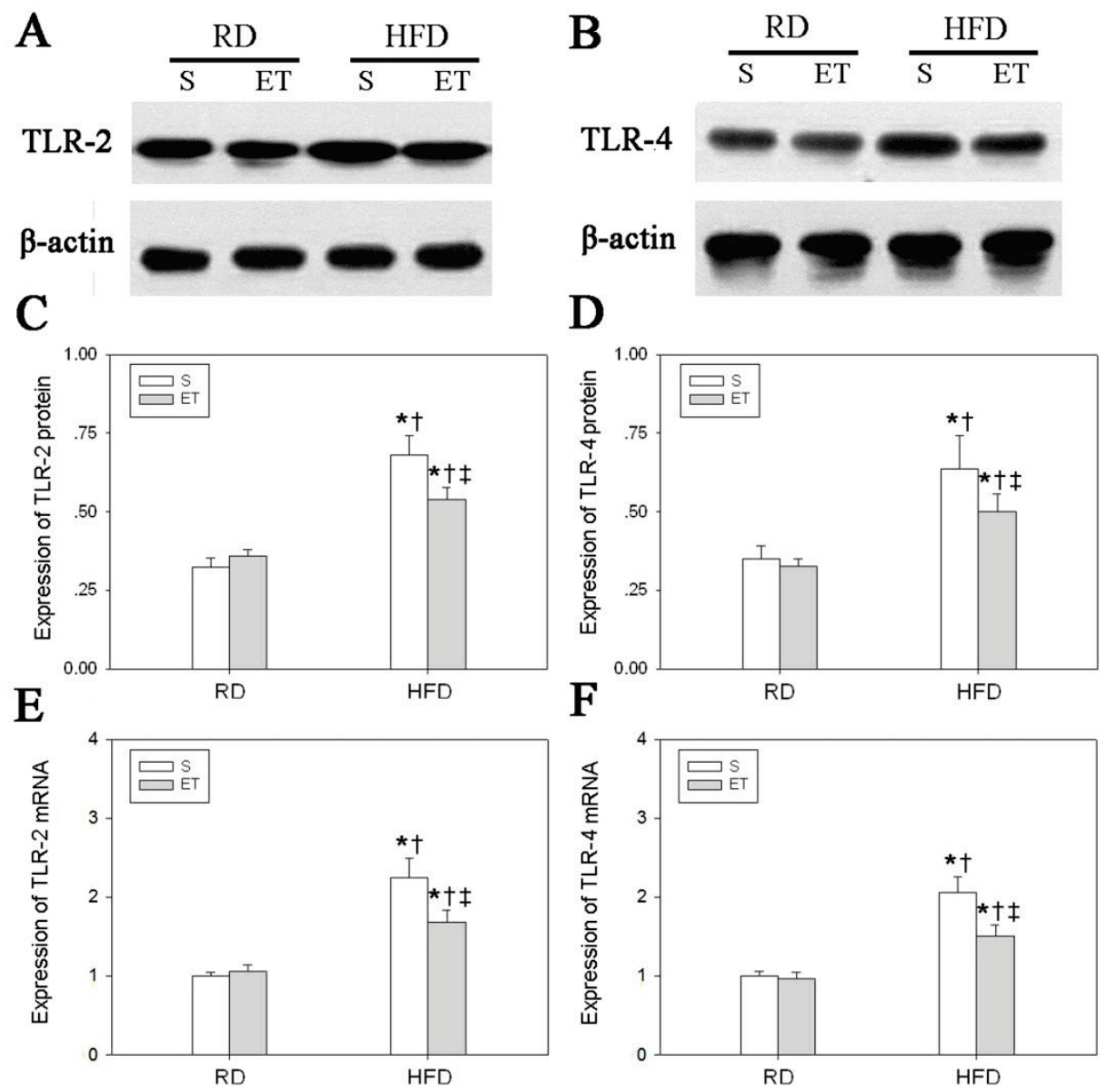

Fig. 5. The TLR-2 and TLR-4 expression in the ventricle muscles of rats with different treatment at the end of the 12 th week of diet. The protein was determined with Western blot and was expressed as the ratio to $\beta$-actin. A, B: Original recording for TLR-2, TLR-4; C, D: Protein levels of TLR-2, TLR-4; E, F: mRNA levels of TLR-2, TLR-4. Values are mean \pm SE; $n=6$ for each group. $* P<0.05$ vs. RD-S; $+\mathrm{P}<0.05$ vs. RD-ET; $¥ \mathrm{P}<0.05$ vs. HFD-S.

\section{Discussion}

The primary findings in the present study are that ET can markedly attenuate sympathetic activation and oxidative stress, and suppress fat accumulation and BW gain in diet-induced obesity. Decreased protein and mRNA levels of TLR-2 and TLR-4 were also observed in obese rats after ET. It is efficient in reducing the risk for hypertension and TLR stimulation in the development of obesity. ET may be a promising strategy in preventing sympathetic activation and oxidative stress in obesity.

It is well known that obesity increases the risk of developing hypertension and other cardiovascular diseases, and excessive sympathetic activity and oxidative stress contributes to the progression of obesity (Bombelli et al. 2011, Kalil and Haynes 2012). The diet-induced obesity model closely mimics many characteristics (e.g. neurohumoral changes, hemodynamics) of human obesity (Dobrian et al. 2000, Northcott et al. 2012). After 12-week diet, the HFD-S rats had a greater final $\mathrm{BW}$ and $\mathrm{BW}$ gains than RD-S rats, and we observed no overlap on between the final BW range of HFD-S and RD-S rats. In addition to the increased fat-free mass, the accretion of BW also entails the excess gains in fat mass in obesity. Similarly, higher inguinal, retroperitoneal, epididymal, mesenteric and total WAT mass were also found in HFD-S rats versus RD-S rats. The above variables indicated the rat model of dietinduced obesity was successfully established. The higher MAP in HFD rats confirmed an important role of obesity in the development of hypertension.

The sympathetic nervous system (SNS) plays an essential role in regulating metabolic and cardiovascular homeostasis. Increased plasma NE was referred as an outcome of enhanced neurotransmitter release secondary to the sympathetic overdrive (Goldstein 1983, Li and Pan 2005). The maximal hexamethonium induced depressor effect is an index of baseline peripheral sympathetic activity (Nagae et al. 2009). We found the NE level was unchanged before and after surgery in normal rats (data 
no shown), as to verify if the surgery has not any influence on NE level. In the present study, higher plasma $\mathrm{NE}$ and greater depressor response to hexamethonium suggested sympathetic activation at the end of the 12th week in this model of obesity. It is particularly worth noting that the ET can mitigate the sympathetic activation in obesity, which may be beneficial to reduce the risk of obesity-related cardiovascular complications.

However, the SNS activity in obesity is controversial, due to the inconsistent findings reported previously (Davy and Orr 2009). Several studies suggested that the low sympathetic activity associated with high parasympathetic activity is greatly involved in the development of obesity (Gomes et al. 2013, Rinaldi et al. 2014). In addition, our results showed a marked sympathetic activation at the end of the 12 th week in this HFD induced obesity, which differed from the previous experiments. It is unclear why the results are inconsistent across studies. However, three important issues should be raised. Firstly, as previously reviewed (Davy and Orr 2009), sympathetic activity activation is characteristic of a number of metabolic and cardiovascular disorders, many of which occur more frequently in obese individuals. In the present study, higher blood pressure in HFD rats versus their controls after 12-week diet indicated a detectable progression and increasing risk for hypertension. Grassi et al. (2000) pointed out that obesity potentiated SNS activation in patients with hypertension. The above evidence heightened the consequences of alterations in SNS behavior in obesity. Secondly, measurements of SNS activity via methods with different sensitivity and specificity may explain why the results concerning the sympathetic activity in obesity were so conflicting. Each technique possessed distinct advantages and disadvantages (Davy and Orr 2009). The SNS activity was evaluated by whole body NE spillover in the present study and nerve electrical signals in the previous studies (Gomes et al. 2013, Rinaldi et al. 2014). The NE spillover may be influenced by the net effect of SNS outflow to all the individual tissues/organs, and the electrical signals recording cannot discriminate afferent from efferent signals (Rinaldi et al. 2014). Therefore, a direct measure of efferent postganglionic sympathetic nerve traffic was recommended in the further research of this area (Wallin and Fagius 1988, Vallbo et al. 2004). Thirdly and foremost, in addition to whole body SNS behavior, the consequences of region specific SNS activation in obesity should also be considered (Vaz et al. 1997, Coppack et al. 1998, Davy and Orr 2009). In human obesity, regional heterogeneity of SNS behavior were observed such as no alteration to splanchnic region, decreased activity to cardiac region, and elevated activity to kidney (Vaz et al. 1997). This may reflect the fact that whole-body measurements do not accurately reflect SNS activity in some tissues/organs.

We observed that ET attenuated the high MAP and caused fat loss. The results indicate the therapeutic effect of ET on the symptoms of obesity. ET with submaximal intensity has been shown to modulate sympathetic activity and maintain the balance between parasympathetic and sympathetic activity in the long term of many diseases (Leosco et al. 2013, Broderick et al. 2014). Based on this information, the regular physical exercise shows beneficial effects and may be a training strategy for this particular patient group. Interestingly, Gomes et al. (2013) demonstrated that continual moderate exercise-training was effective at preventing a BW increase and fat accumulation in both control and HFD groups in comparison to their respective sedentary groups, which differs from our findings in the current study. Several factors may account for this inconsistency. First, different age and species of animal were used in the current (adult SD rats) and previous reported experiments (recently weaned Wistar rats). Kobayashi et al. (2012) found a genetic strain-dependent reactivity to mechanical stimuli in skeletal muscle between SD and Wistar rats. In addition, aging can influence the neuromuscular adaptations to resistance training (Deschenes et al. 2015). It is possible that the age and species of rats may have the potential to influence the response to the ET, thus mediating the metabolic crosstalk between fat and muscle. Second, varied exercise protocols may explain the divergent results across studies. Gomes RM et al. (2013) chose a training program with adjustments in speed $(10-20 \mathrm{~m} / \mathrm{min})$ and time $(10-60 \mathrm{~min})$ in total 30 sessions for 10 weeks, while the rats in the present study were trained on a motorized treadmill at $18 \mathrm{~m} / \mathrm{min}$ for $60 \mathrm{~min} /$ day, five days/week for 8 weeks. The intensity and amount of ET may lead to obvious different extents of improvement of weight gain and fat accumulation. We failed to find the normalization of BW in HFD-rats, possibly due to the lack of long-term observation. It is hypothesized that the HFD rats can also regain normal WAT fat mass and BW as control animals when trained for a longer time. It is a limitation of our study and the relative experiment will be carried out in the future. Finally, a relatively high baseline BW in the present study may be another reason for this inconformity. 
Moreover, previous studies that demonstrated that moderate exercise in rats under regular diet induce decrease in MAP and NE, different from our findings in the current study. We speculated three major issues mentioned above can also explain the discrepancy.

Our results showed that ET can attenuate sympathetic activation in diet-induced obesity, while Gomes et al. (2013) demonstrated that treadmill exercise increased the triggering rate of sympathetic branch nerve in obese rats. We inferred that the different observation time points may account for this inconsistency. One study used neonatal mice to induce obesity during their first 5 days of life (Scomparin et al. 2009). Other studies chose weaning and post-weaning rats to induce obesity, respectively (Gomes et al. 2013, Rinaldi et al. 2014). However, in the present study, adult normotensive rats weighing between 300 and $350 \mathrm{~g}$ were used to induce obesity with a HFD for 12 weeks. After 12-week diet, the blood pressure of HFD-rats was higher than their controls, indicating the onset of cardiovascular disorders due to the chronic sympathetic overactivity. As previously reviewed (Davy and Orr 2009), sympathetic overactivity is accompanied by the elevated sympathetic outflow to organs such as the heart, kidneys, and blood vessels (Smith and Minson 2012, Messina et al. 2013). Moreover, it can contribute to a further decline of insulin sensitivity, creating a vicious cycle that may promote the development of the metabolic syndrome and hypertension. Sympathetic activity plays a crucial role in the control of energy balance and BW (Smith and Minson 2012, Messina et al. 2013), so when the ET causes BW loss and energy expenditure, the excess sympathetic activity is consequentially attenuated.

Oxidative stress plays a critical role in the progression of obesity, which is deleterious in its complications (Dobrian et al. 2004). Elevated NADPH oxidase levels can be found in many tissues (e.g. vascular, kidney or adipose) in obese adults or rats (Silver et al. 2007, Jiang et al. 2011). Intracerebroventricular or periphery intervention of antioxidant showed beneficial effects on the obesity-related symptoms, indicating antioxidant protection should be provided for the obesity (Pung et al. 2012, Fabbrini et al. 2014). In order to clarify whether ET can alleviate the oxidative stress in obese rats, the MDA, superoxide anion and F2-IsoPs levels are measured in muscles and serum. We found that MDA, superoxide anion and F2-IsoPs were increased in serum, soleus and ventricle muscles of HFD-S rats after 12th week of diet, which can be decreased by ET. The above results indicated that ET facilitated the elimination of superoxide anion and subsequently reduced oxidative stress. Furthermore, weight loss after ET in obese rats is not only due to decreased appetite and food consumption, but also an increase in thermogenesis and activity level.

TLRs are transmembrane proteins involved in the crosstalk between the immune systems and body metabolism (Francaux 2009, Frisard et al. 2010). Increased TLRs activity was reported in metabolic disease, such as metabolic syndrome, type 2 diabetes mellitus and obesity (Milanski et al. 2009). TLR stimulation plays a crucial role in the pathogenesis of obesity (Francaux 2009). In order to clarify whether ET can alleviate the TLR stimulation in obese rats, we measure the protein and mRNA levels of TLR-2 and TLR-4 in muscles. The results showed that both protein and mRNA levels of TLR-2 and TLR-4 were increased in muscles of HFD-S rats after 12th week of diet. This may be due to a potential pathophysiological link between TLRs and obesity leading to sympathetic activation and oxidative stress. The elevated levels of TLR-2 and TLR-4 can be ameliorated by ET, indicating that ET could inhibit the activation of TLR signaling.

In summary, we have demonstrated that ET markedly attenuates sympathetic activation and oxidative stress and suppress fat accumulation and BW gain in dietinduced obesity. ET is efficient in reducing the risk for hypertension in the development of obesity. Taken together, our results provide evidence that ET can prevent the sympathetic activation and oxidative stress in the obesity with the possible mechanisms of down regulating the protein levels of TLR-2 and TLR-4.

\section{Conflict of Interest}

There is no conflict of interest.

\section{Acknowledgements}

This work was supported by the Sports Science Association Foundation (1105085) of Jilin Province, China.

\section{Abbreviations}

HFD, high-fat diet; RD, regular diet; S, sedentary; MDA, malondialdehyde; TLR, toll-like receptor; BW, body weight; SBP, systolic blood pressure; NE, norepinephrine; SOD, superoxide dismutase; MLU, mean light unit; OD, optical density; SD, Sprague-Dawley; SNS, sympathetic nervous system; DHE, dihydroethidium; PBS, phosphate-buffered saline; MAP, mean arterial pressure; WAT, white adipose tissue. 


\section{References}

BOMBELLI M, FACCHETTI R, SEGA R, CARUGO S, FODRI D, BRAMBILLA G, GIANNATTASIO C, GRASSI G, MANCIA G: Impact of body mass index and waist circumference on the long-term risk of diabetes mellitus, hypertension, and cardiac organ damage. Hypertension 58: 1029-1035, 2011.

BRODERICK TL, WANG D, JANKOWSKI M, GUTKOWSKA J: Unexpected effects of voluntary exercise training on natriuretic peptide and receptor mRNA expression in the ob/ob mouse heart. Regul Pept 188: 52-59, 2014.

CHOU WC, JIE C, KENEDY AA, JONES RJ, TRUSH MA, DANG CV: Role of NADPH oxidase in arsenic-induced reactive oxygen species formation and cytotoxicity in myeloidleukemia cells. Proc Natl Acad Sci USA 101: 4578-4583, 2004.

COPPACK SW, HOROWITZ JF, PARAMORE DS, CRYER PE, ROYAL HD, KLEIN S: Whole body, adipose tissue, and forearm norepinephrine kinetics in lean and obese women. Am J Physiol Endo Metab 275: 830-834, 1998.

DAVY KP, ORR JS: Sympathetic nervous system behavior in human obesity. Neurosci Biobehav Rev 33: 116-124, 2009.

DESCHENES MR, SHERMAN EG, ROBY MA, GLASS EK, HARRIS MB: Effect of resistance training on neuromuscular junctions of young and aged muscles featuring different recruitment patterns. $J$ Neurosci Res 93: 504-513, 2015.

DOBRIAN AD, DAVIES MJ, PREWITT RL, LAUTERIO TJ: Development of hypertension in a rat model of dietinduced obesity. Hypertension 35: 1009-1015, 2000.

DOBRIAN AD, SCHRIVER SD, KHRAIBI AA, PREWITT RL: Pioglitazone prevents hypertension and reduces oxidative stress in diet-induced obesity. Hypertension 43: 48-56, 2004.

DORRESTEIJN JA, VISSEREN FL, SPIERING W: Mechanisms linking obesity to hypertension. Obes Rev 13: 17-26, 2012.

FABBRINI E, SERAFINI M, COLIC BARIC I, HAZEN SL, KLEIN S: Effect of plasma uric acid on antioxidant capacity, oxidative stress, and insulin sensitivity in obese subjects. Diabetes 63: 976-981, 2014.

FAGARD RH: Physical activity in the prevention and treatment of hypertension in the obese. Med Sci Sports Exerc 31: 624-630, 1999.

FAN ZD, ZHANG L, SHI Z, GAN XB, GAO XY, ZHU GQ: Artificial microRNA interference targeting AT(1a) receptors in paraventricular nucleus attenuates hypertension in rats. Gene Ther 19: 810-817, 2012.

FRANCAUX M: Toll-like receptor signalling induced by endurance exercise. Appl Physiol Nutr Metab 34: 454-458, 2009.

FRESNO M, ALVAREZ R, CUESTA N: Toll-like receptors, inflammation, metabolism and obesity. Arch Physiol Biochem 117: 151-164, 2011.

FRISARD MI, MCMILLAN RP, MARCHAND J, WAHLBERG KA, WU Y, VOELKER KA, HEILBRONN L, HAYNIE K, MUOIO B, LI L, HULVER MW: Toll-like receptor 4 modulates skeletal muscle substrate metabolism. Am J Physiol Endocrinol Metab 298: 988-998, 2010.

FURUKAWA S, FUJITA T, SHIMABUKURO M, IWAKI M, YAMADA Y, NAKAJIMA Y, NAKAYAMA O, MAKISHIMA M, MATSUDA M, SHIMOMURA I: Increased oxidative stress in obesity and its impact on metabolic syndrome. J Clin Invest 114: 1752-1761, 2004.

GOLDSTEIN DS: Plasma catecholamines and essential hypertension. An analytical review. Hypertension 5: 86-99, 1983.

GOMES RM, TÓFOLO LP, RINALDI W, SCOMPARIN DX, GRASSIOLLI S, BARELLA LF, DE OLIVEIRA JC, BRANCO RC, AGOSTINHO AR, RIBEIRO TA, GRAVENA C, MATHIAS PC: Moderate exercise restores pancreatic beta-cell function and autonomic nervous system activity in obese ratsinduced by high-fat diet. Cell Physiol Biochem 32: 310-321, 2013.

GRASSI G, SERAVALLE G, DELL'ORO R, TURRI C, BOLLA GB, MANCIA G: Adrenergic and reflex abnormalities in obesity-related hypertension. Hypertension 36: 538-542, 2000.

HUSSEIN AM, ABD-ELKHABIR A, ABOZAHRA A, BAIOMY A, ASHAMALLAH SA, SHEASHAA HA, SOBH MA: Pancreatic injury secondary to renal ischemia/reperfusion (I/R) injury: possible role of oxidative stress. Physiol Res 63: 47-55, 2014. 
JIANG F, LIM HK, MORRIS MJ, PRIOR L, VELKOSKA E, WU X, DUSTING GJ: Systemic upregulation of NADPH oxidase in diet-induced obesity in rats. Redox Rep 16: 223-229, 2011.

KALIL GZ, HAYNES WG: Sympathetic nervous system in obesity-related hypertension: mechanisms and clinical implications. Hypertens Res 35: 4-16, 2012.

KLEIBER AC, ZHENG H, SCHULTZ HD, PEULER JD, PATEL KP: Exercise training normalizes enhanced glutamate-mediated sympathetic activation from the PVN in heart failure. Am J Physiol Regul Integr Comp Physiol 294: 1863-1872, 2008.

KOBAYASHI K, OGASAWARA R, TSUTAKI A, LEE K, OCHI E, NAKAZATO K: Genetic strain-dependent protein metabolism and muscle hypertrophy under chronic isometric training in rat gastrocnemius muscle. Physiol Res 61: 527-535, 2012.

LAMBERT GW, STRAZNICKY NE, LAMBERT EA, DIXON JB, SCHLAICH MP: Sympathetic nervous activation in obesity and the metabolic syndrome - causes, consequences and therapeutic implications. Pharmacol Ther 126: 159-172, 2010.

LAMBERT E, SARI CI, DAWOOD T, NGUYEN J, MCGRANE M, EIKELIS N, CHOPRA R, WONG C, CHATZIVLASTOU K, HEAD G, STRAZNICKY N, ESLER M, SCHLAICH M, LAMBERT G: Sympathetic nervous system activity is associated with obesity-induced subclinical organ damage in young adults. Hypertension 56: 351-358, 2010.

LEOSCO D, PARISI V, FEMMINELLA GD, FORMISANO R, PETRAGLIA L, ALLOCCA E, BONADUCE D: Effects of exercise training on cardiovascular adrenergic system. Front Physiol 4: 348, 2013.

LI DP, PAN HL: Angiotensin II attenuates synaptic GABA release and excites paraventricular-rostral ventrolateral medulla output neurons. J Pharmacol Exp Ther 313: 1035-1045, 2005.

MELO SF, LUNZ W, FONTES EP, DIAS CM, CARNEIRO MA JR, MOURA AG, DEL CARLO RJ, NATALI AJ: Different levels of Hsp72 in female rat myocardium in response to voluntary exercise and forced exercise. Arq Bras Cardiol 93: 456-462, 2009.

MESSINA G, DE LUCA V, VIGGIANO A, ASCIONE A, IANNACCONE T, CHIEFFI S, MONDA M: Autonomic nervous system in the control of energy balance and body weight: personal contributions. Neurol Res Int 2013: 639280, 2013.

MILANSKI M, DEGASPERI G, COOPE A, MORARI J, DENIS R, CINTRA DE, TSUKUMO DM, ANHE G, AMARAL ME, TAKAHASHI HK, CURI R, OLIVEIRA HC, CARVALHEIRA JB, BORDIN S, SAAD MJ, VELLOSO LA: Saturated fatty acids produce an inflammatory response predominantly through the activation of TLR4 signaling in hypothalamus: implications for the pathogenesis of obesity. $J$ Neurosci 29: 359-370, 2009.

MUELLENBACH EA, DIEHL CJ, TEACHEY MK, LINDBORG KA, ARCHULETA TL, HARRELL NB, ANDERSEN G, SOMOZA V, HASSELWANDER O, MATUSCHEK M, HENRIKSEN EJ: Interactions of the advanced glycation end product inhibitor pyridoxamine and the antioxidant alpha-lipoic acid on insulin resistance in the obese Zucker rat. Metabolism 57: 1465-1472, 2008.

NAGAE A, FUJITA M, KAWARAZAKI H, MATSUI H, ANDO K, FUJITA T: Sympathoexcitation by oxidative stress in the brain mediates arterial pressure elevation in obesity-induced hypertension. Circulation 119: 978-986, 2009.

NAGAI N, MORITANI T: Effect of physical activity on autonomic nervous system function in lean and obese children. Int J Obes Relat Metab Disord 28: 27-33, 2004.

NAVARRO A, GOMEZ C, LÓPEZ-CEPERO JM, BOVERIS A: Beneficial effects of moderate exercise on mice aging: survival, behavior, oxidative stress, and mitochondrial electron transfer. Am J Physiol Regul Integr Comp Physiol 286: 505-511, 2004.

NORTHCOTT CA, FINK GD, GARVER H, HAYWOOD JR, LAIMON-THOMSON EL, MCCLAIN JL, PIRES PW, RAINEY WE, RIGSBY CS, DORRANCE AM: The development of hypertension and hyperaldosteronism in a rodent model of life-long obesity. Endocrinology 153: 1764-1773, 2012.

PUNG YF, ROCIC P, MURPHY MP, SMITH RA, HAFEMEISTER J, OHANYAN V, GUARINI G, YIN L, CHILIAN WM: Resolution of mitochondrial oxidative stress rescues coronary collateral growth in Zucker obese fatty rats. Arterioscler Thromb Vasc Biol 32: 325-334, 2012. 
RINALDI W, GOMES RM, SCOMPARIN DX, GRASSIOLLI S, RIBEIRO TA, FABRICIO GS, BARELLA LF, PAVANELLO A, TROMBINI AB, MATHIAS PC, DE OLIVEIRA JC: Low-intensity and moderate exercise training improves autonomic nervous system activity imbalanced bypostnatal early overfeeding in rats. $J$ Int Soc Sports Nutr 11: 25, 2014.

ROVEDA F, MIDDLEKAUFF HR, RONDON MU, REIS SF, SOUZA M, NASTARI L, BARRETTO AC, KRIEGER EM, NEGRÃO CE: The effects of exercise training on sympathetic neural activation in advanced heart failure: a randomized controlled trial. J Am Coll Cardiol 42: 854-860, 2003.

SCHREIHOFER AM, HAIR CD, STEPP DW: Reduced plasma volume and mesenteric vascular reactivity in obese Zucker rats. Am J Physiol Regul Integr Comp Physiol 288: 253-261, 2005.

SCOMPARIN DX, GOMES RM, GRASSIOLLI S, RINALDI W, MARTINS AG, DE OLIVEIRA JC, GRAVENA C, DE FREITAS MATHIAS PC: Autonomic activity and glycemic homeostasis are maintained by precocious and low intensity training exercises in MSG-programmed obese mice. Endocrine 36: 510-517, 2009.

SILVER AE, BESKE SD, CHRISTOU DD, DONATO AJ, MOREAU KL, ESKURZA I, GATES PE, SEALS DR: Overweight and obese humans demonstrate increased vascular endothelial NAD(P)H oxidase-p47(phox) expression and evidence of endothelial oxidative stress. Circulation 115: 627-637, 2007.

SMITH MM, MINSON CT: Obesity and adipokines: effects on sympathetic overactivity. $J$ Physiol 590: 1787-1801, 2012.

STEWART KJ: Exercise training and the cardiovascular consequences of type 2 diabetes and hypertension: plausible mechanisms for improving cardiovascular health. JAMA 88: 1622-1631, 2002.

VALLBO AB, HAGBARTH KE, WALLIN BG: Microneurography: how the technique developed and its role in the investigation of the sympathetic nervous system. J Appl Physiol 96: 1262-1269, 2004.

VAZ M, JENNINGS G, TURNER A, COX H, LAMBERT G, ESLER M: Regional sympathetic nervous activity and oxygen consumption in obese normotensive human subjects. Circulation 96: 3423-3429, 1997.

VERNUNFT A, VIERGUTZ T, PLINSKI C, WEITZEL JM: Postpartum levels of 8-iso-prostaglandin F2 $\alpha$ in plasma and milk phospholipid fractions as biomarker of oxidative stress in first-lactating dairy cows. Prostaglandins Other Lipid Mediat 112: 34-38, 2014.

WALLIN BG, FAGIUS J: Peripheral sympathetic neural activity in conscious humans. Annu Rev Physiol 50: 565-576, 1988.

WOFFORD MR, ANDERSON DC JR, BROWN CA, JONES DW, MILLER ME, HALL JE: Antihypertensive effect of alpha- and beta-adrenergic blockade in obese and lean hypertensive subjects. Am J Hypertens 14: 694-698, 2001.

YAMAGUCHI S, AOYAMA T, ITO A, NAGAI M, IIJIMA H, ZHANG X, TAJINO J, KUROKI H: Effects of exercise level on biomarkers in a rat knee model of osteoarthritis. J Orthop Res 31: 1026-1031, 2013.

ZIMMERMAN MC, LAZARTIGUES E, SHARMA RV, DAVISSON RL: Hypertension caused by angiotensin II infusion involves increased superoxide production in the central nervous system. Circ Res 95: 210-216, 2004. 